\title{
Persistent $\mathrm{M} 2$ phase in strongly strained (01 1)-oriented grains in $\mathrm{VO}_{2}$ films grown on sapphire (001) in reactive sputtering
}

\author{
Cite as: J. Appl. Phys. 125, 165304 (2019); doi: 10.1063/1.5068700 \\ Submitted: 18 October 2018 - Accepted: 29 March 2019 . \\ Published Online: 24 April 2019
}

Kohei Matsuoka, ${ }^{7}$ Kunio Okimura, ${ }^{1, a)}$ Nurul Hanis Azhan, ${ }^{2}$ (D) Mustapha Zaghrioui, ${ }^{3}$ (iD) and Joe Sakai ${ }^{4}$ (D)

\author{
AFFILIATIONS \\ ${ }^{1}$ Graduate School of Engineering, Tokai University, Hiratsuka 259-1292, Japan \\ ${ }^{2}$ Electrical Engineering Section, Universiti Kuala Lumpur British Malaysian Institute, 53100 Gombak, Selangor, Malaysia \\ ${ }^{3}$ Laboratoire GREMAN CNRS-UMR 7347, IUT de BLOIS, 15, rue de la Chocolaterie, C. S. 32903, 41029 Blois Cedex, France \\ ${ }^{4}$ Institut Català de Nanociència i Nanotecnologia (ICN2), ICN2 Building, UAB Campus, 08193 Bellaterra, Spain
}

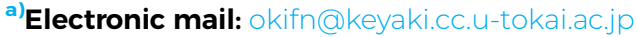

\begin{abstract}
We report on the first observation of the persistent M2 phase in strongly strained (011)-oriented grains in $\mathrm{VO}_{2}$ films grown on $\mathrm{Al}_{2} \mathrm{O}_{3}$ (001) substrates by means of conventional rf reactive sputtering under adequate deposition conditions. Spatially resolved micro-Raman spectra clearly showed that (011)-oriented large crystalline grains with the $c_{\mathrm{R}}$-axis parallel to the substrate resulted in the appearance of the $\mathrm{M} 2$ phase over a wide temperature range of $30^{\circ} \mathrm{C}$. A close correlation of the appearance range of the M2 phase with the in-plane tensile stress of (011)-oriented grains was revealed by X-ray diffraction. We present a phase diagram for the M1, M2, and R phases in relation to the stress of (011)-oriented grains and temperature. It was shown that (011)-oriented micrometer-sized long grains play a crucial role in the emerging structural phase transition (SPT) via an $\mathrm{M} 2$ phase even in a film grown on $\mathrm{Al}_{2} \mathrm{O}_{3}$ (001), which is ordinarily reserved for the (020)-oriented $\mathrm{VO}_{2}$ growth. The results shown here will contribute to make clear the conditions for obtaining $\mathrm{VO}_{2}$ films with the appearance of the M2 phase in their SPT process.
\end{abstract}

Published under license by AIP Publishing. https://doi.org/10.1063/1.5068700

\section{INTRODUCTION}

A strongly correlated oxide, called vanadium dioxide $\left(\mathrm{VO}_{2}\right)$, has been generating a wide range of interest because of the drastic changes taking place in physical properties that are concomitant with the insulator-metal transition (IMT) phenomenon and the utilization of such changes in engineering applications. ${ }^{1-3}$ Attempts have been made over several decades to study the correlation between the IMT and the structural phase transition (SPT) in order to realize the desired properties of $\mathrm{VO}_{2}{ }^{4,5}$ In addition, recently, growing interest for the application of the IMT to electrical, optical, and thermal devices has been related to the controllability of the IMT in $\mathrm{VO}_{2}$ thin films. ${ }^{6-11} \mathrm{New}$ attempts to apply the IMT for neuromorphic computing and terahertz switching require further understanding of the physics of the thin film $\mathrm{VO}_{2}$.

So far, a number of studies on $\mathrm{VO}_{2}$ single crystals and $\mathrm{VO}_{2}$ films have suggested that the distance of $\mathrm{V}$ atoms along the $c_{\mathrm{R}}$-axis (in the high-temperature tetragonal phase, $\mathrm{R}$ phase) determines the IMT temperature. ${ }^{16-18} \mathrm{VO}_{2}$ films grown on $\mathrm{TiO}_{2}(001)$ substrates, in which the IMT occurs at room temperature (around $300 \mathrm{~K}$ ), contribute to enhancing the applicability of $\mathrm{VO}_{2}$ films. ${ }^{19}$ However, the appearance of an intermediate phase in the SPT pathway between the monoclinic $\mathrm{M} 1$ phase and the tetragonal R phase, especially, in $\mathrm{VO}_{2}$ thin films, remains unresolved. ${ }^{20-25}$ Conditions for the appearance of the intermediate $\mathrm{M} 2$ phase with a monoclinic symmetry have been intensively investigated by many authors by using $\mathrm{VO}_{2}$ singlecrystalline nanorods (usually called nanobeams). ${ }^{26-31}$ Phase diagrams as functions of temperature and stress along the $c_{\mathrm{R}}$-axis have been displayed for the SPT of single-crystalline $\mathrm{VO}_{2} \cdot{ }^{28,30}$ As for $\mathrm{VO}_{2}$ films grown on various substrates, the appearance of the M2 phase strongly depends on deposition conditions, which affect the stress on the $\mathrm{VO}_{2}$ films. ${ }^{32,33}$ Polycrystalline $\mathrm{VO}_{2}$ films have grain boundaries, even though they are composed of highly oriented grains, giving rise 
to a complicated situation of stress state acting on the grains. ${ }^{33,34}$ In addition, the coexistence of the $\mathrm{V}_{\mathrm{n}} \mathrm{O}_{2 \mathrm{n}-1}$ and $\mathrm{V}_{\mathrm{n}} \mathrm{O}_{2 \mathrm{n}+1}$ phases different from that of the stoichiometric $\mathrm{VO}_{2}$ invites difficulties for considering the relation between the stress and the $\mathrm{M} 2$ phase. ${ }^{35,36}$

$\mathrm{Al}_{2} \mathrm{O}_{3}$ (001) substrates are frequently utilized for the growth of $\mathrm{VO}_{2}$ films in which $b_{\mathrm{M}}$-axis (in the low-temperature monoclinic $\mathrm{M} 1$ phase) oriented $\mathrm{VO}_{2}$ grains are grown with in-plane three directions based on the lattice matching between the hexagonal plane of $\mathrm{Al}_{2} \mathrm{O}_{3}$ (001) and the $a_{\mathrm{M}^{-}} c_{\mathrm{M}}$ plane of $\mathrm{VO}_{2} \cdot{ }^{37}$ Since the $c_{\mathrm{R}}$-axis $\left(a_{\mathrm{M}}\right.$-axis) is parallel to the $\mathrm{Al}_{2} \mathrm{O}_{3}$ (001) plane, stress on the $\mathrm{VO}_{2}$ film acts on the $\mathrm{V}-\mathrm{V}$ chains, giving rise to the possibilities of inducing the $\mathrm{M} 2$ phase if strong tensile stress remains in the film. Thery et al. reported the SPT via an $\mathrm{M} 2$ phase in relatively thin $\mathrm{VO}_{2}$ films on $\mathrm{Al}_{2} \mathrm{O}_{3}(001)$ deposited by electron-beam evaporation due to the tensile stress, which originates in the difference of the thermal expansion coefficient between $\mathrm{VO}_{2}$ and $\mathrm{Al}_{2} \mathrm{O}_{3} \cdot{ }^{32}$ We also reported that the SPT with the intermediate $\mathrm{M} 2$ phase was observed in the $\mathrm{VO}_{2}$ film on $\mathrm{Al}_{2} \mathrm{O}_{3}$ (001) deposited by biased reactive sputtering. ${ }^{36,38}$ The films we obtained were dominated by (011)-oriented large crystalline domains, which underwent SPT with the M2 phase. The temperature range of the appearance of the M2 phase was as narrow as 10$15^{\circ} \mathrm{C}$. Based on these studies, the fact that the tensile stress on the $c_{\mathrm{R}}$-axis induces SPT with the M2 phase even in thin films was observed. However, the correlation between the stress strength and the temperature range of the appearance of M2 phase was unclear due to the presence of a disorder and the grain boundaries in the $\mathrm{VO}_{2}$ film on the substrate. Grain boundaries reduce stress on the $\mathrm{VO}_{2}$ grains, especially, in the case of $\mathrm{VO}_{2}$ on $\mathrm{Al}_{2} \mathrm{O}_{3}$ (001), because of restricted small grain sizes. Thus, it is highly desirable to observe the effect of tensile stress on the appearance of the M2 phase directly in the $\mathrm{VO}_{2}$ film on $\mathrm{Al}_{2} \mathrm{O}_{3}(001)$.

In this article, we show the case in which (011)-oriented long platelike grains were grown on $\mathrm{Al}_{2} \mathrm{O}_{3}$ (001) substrates under adequate deposition conditions in conventional reactive sputtering. We demonstrate that the (011)-oriented grains underwent SPT with a persistent $\mathrm{M} 2$ phase over $30^{\circ} \mathrm{C}$ through the micro-Raman observations for the particular grains. A phase diagram for M1, M2, and R phases in relation between the stress on the (011)-oriented grains and the temperature is shown. We discuss the correlation of the appearance of the $\mathrm{M} 2$ phase in $\mathrm{VO}_{2}$ films grown on $\mathrm{Al}_{2} \mathrm{O}_{3}(001)$.

\section{EXPERIMENTAL METHODS}

$\mathrm{VO}_{2}$ films were deposited by conventional radio frequency (rf) magnetron sputtering. In this study, we did not utilize substrate biasing that we introduced before. ${ }^{36}$ Polished $\mathrm{Al}_{2} \mathrm{O}_{3}$ (001) was used as the substrate and was placed at the center position on the lower electrode. The temperature of the substrate and the rf power fed to the metal vanadium (99.9\%) target with a diameter of $100 \mathrm{~mm}$ were $450{ }^{\circ} \mathrm{C}$ and $200 \mathrm{~W}$, respectively. The flow rates of $\mathrm{Ar}$ and $\mathrm{O}_{2}$ gases were 38 and $1 \mathrm{sccm}$, respectively. The total pressure of $\mathrm{Ar}$ and $\mathrm{O}_{2}$ gases was $0.5 \mathrm{~Pa}$. We varied the deposition period as 10,20 , and $30 \mathrm{~min}$.

Crystalline structures of $\mathrm{VO}_{2}$ films were analyzed by X-ray diffraction (XRD; Philips, X'pert MRD) with $\mathrm{CuK} \alpha \mathrm{X}$-ray source $(\lambda=1.5418 \AA)$. Temperature-dependent micro-Raman measurements were also done to investigate the SPT at a particular crystalline region. The Raman setup utilizes a $514 \mathrm{~nm}$ Ar ion laser with a power of $0.5 \mathrm{~mW}$ as the light source. The incident laser light was focused by a $\times 50$ lens $(0.50 \mathrm{NA})$, which realizes the spatial resolution of around $2 \mu \mathrm{m} .{ }^{39}$ Reflex device (Renishaw, inVia) and a temperature controller (Linkam, THMS 600) were introduced for temperature-controlled Raman measurements. Field emission scanning electron microscopy (FE-SEM; Hitachi, S-4800) was used for observing both the surface and the cross-sectional morphologies of the $\mathrm{VO}_{2}$ films. Atomic force microscopy (AFM; Shimadzu, SPM-9700) was also utilized to observe crystalline growth aspects and minute surface roughness. Electron probe microscopy analysis (EPMA; Shimadzu, EPMA-1610) was introduced to investigate spatial difference of the atomic concentration. Resistance changes against temperature were measured by two electrical probe tips, which are made of tungsten carbide (WC). Film thickness was evaluated by cross-sectional SEM images.

\section{RESULTS AND DISCUSSION}

Figure 1 shows XRDs for $\mathrm{VO}_{2}$ films deposited for different periods of 10,20 , and $30 \mathrm{~min}$. We named these samples as S1 (10 min), S2 (20 min), and S3 (30 min). Film thicknesses were 100, 290 , and $340 \mathrm{~nm}$ for S1, S2, and S3, respectively. In all samples, we see diffraction from the $\mathrm{VO}_{2}(020)$ plane at around $2 \theta=39.8^{\circ}$, whose FWHM of rocking curves was $0.09^{\circ}, 0.14^{\circ}$, and $0.11^{\circ}$ for $\mathrm{S} 1$, $\mathrm{S} 2$, and S3, respectively. The growth of (020)-oriented $\mathrm{VO}_{2}$ films on $\mathrm{Al}_{2} \mathrm{O}_{3}$ (001) is commonly known in addition to the in-plane three growth directions based on lattice matching between $a_{\mathrm{M}}$ and $c_{\mathrm{M}}$ plane with a $\beta$ angle of $122^{\circ}$ and the hexagonal $\mathrm{Al}_{2} \mathrm{O}_{3}(001)$ plane. A large shift $\left(2 \theta=39.98^{\circ}, d_{(020)}=2.255 \AA\right.$ against bulk $2 \theta=39.83^{\circ}, d_{(020)}=2.263 \AA$ ) of the XRD peak position for $(020)$ in the sample S1 means the occurrence of a strong in-plane tensile stress, which is basically caused by the thermal stress. As suggested by many researchers, a large difference of the thermal expansion coefficient between $\mathrm{VO}_{2}\left(29.7 \times 10^{-6} / \mathrm{K}\right.$ along the $c_{\mathrm{R}}$-axis in the tetragonal phase) and $\mathrm{Al}_{2} \mathrm{O}_{3}\left(5.0 \times 10^{-6} / \mathrm{K}\right)$ results in a large tensile stress. $^{32} \mathrm{~A}$ simple estimation of the in-plane thermal stress of a $\mathrm{VO}_{2}$ film with the $c_{\mathrm{R}}$-axis parallel to the $\mathrm{Al}_{2} \mathrm{O}_{3}$ (001) substrate gives $-1.10 \mathrm{GPa}$ at a temperature of $70^{\circ} \mathrm{C}$ for the deposition temperature of $450^{\circ} \mathrm{C}$ when we use Young's modulus $E$ of $140 \mathrm{GPa}$. Thery et al. showed the relaxation of the in-plane tensile strain with an increase of $\mathrm{VO}_{2}$ film thickness deposited by the electron-beam evaporation method, where residual stress is dominated by thermal stress, with relaxation occurring with increasing thickness. ${ }^{32}$ However, in our experiment using reactive sputtering, where energetic ions assist crystalline growth, the (011)-oriented $\mathrm{VO}_{2}$ growth also appeared at deposition periods of 20 and $30 \mathrm{~min}$, as shown in Fig. 1.

We see strong diffraction peaks from $\mathrm{VO}_{2}(011)$ at around $2 \theta=27.9^{\circ}$ for S2 and S3, in Fig. 1(b). As shown in Fig. 1(c), rocking curves for the (011) plane showed small values of FWHM of $0.13^{\circ}$ and $0.10^{\circ}$ for S2 and S3, respectively, indicating a superior orientation of the grains. In addition, the higher peak position of (011) of S2 $\left(2 \theta=27.955^{\circ}, d_{(011)}=3.1916 \AA\right.$, against bulk $2 \theta=27.85^{\circ}$, $\left.d_{(011)}=3.2034 \AA\right)$ suggested a strong in-plane tensile stress on the (011)-oriented grains. The fact that the in-plane tensile stress estimated by the shift of the (020) peak was rather relaxed in S2 compared to that in S1 suggested the difference of stress between 

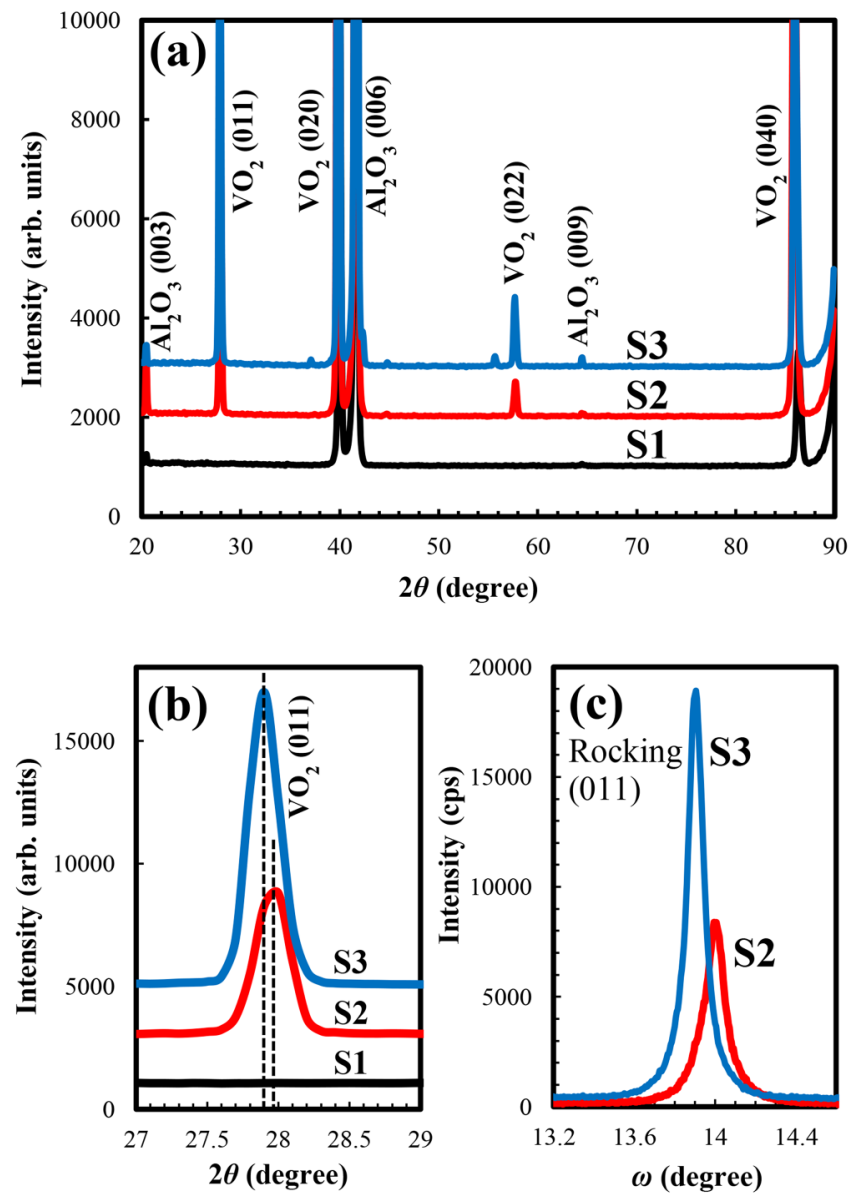

FIG. 1. (a) X-ray diffraction patterns for $\mathrm{VO}_{2}$ films with the deposition time of 10, 20, and 30 min, namely, S1, S2, and S3. (b) Enlarged XRD patterns for the (011) peak. (c) X-ray rocking curves for the (011) peak in S2 and S3.

$\mathrm{VO}_{2}(020)$ and (011) crystalline grains. It is known that the stress in polycrystalline films differs between crystallite and grain boundaries. ${ }^{40}$ We elucidate that the stress of sample S2 depends on crystallites with different sizes as evidenced later by SEM images. The higher peak position of (011) at $2 \theta=27.955^{\circ}$ in S2 corresponds to the out-of-plane compression $\varepsilon_{\mathrm{z}}$ of $-0.37 \%$, which is caused by the in-plane tensile stress $\sigma_{/ /}$based on the elastic-body approximation. We adopted the well-known relationship of $\sigma_{/ /}=-E \varepsilon_{z} / 2 v$, where $v$ is Poisson's ratio, for deriving the in-plane stress. By using the reported values of $E$ and $v$ of $140 \mathrm{GPa}$ and $0.30,{ }^{42,43}$ a tensile stress of $860 \mathrm{MPa}$ was obtained for the (011)-oriented grains. On the other hand, the peak position of (011) in S3 was almost in accordance with that of the bulk $\mathrm{VO}_{2}$, suggesting that the stress on the (011)-oriented grains was relaxed in this sample through the increase of film thickness.

Figure 2 shows FE-SEM images of $\mathrm{VO}_{2}$ films for $\mathrm{S} 1, \mathrm{~S} 2$, and S3. Noticeable grains cannot be seen in S1, as shown in Fig. 2(a),
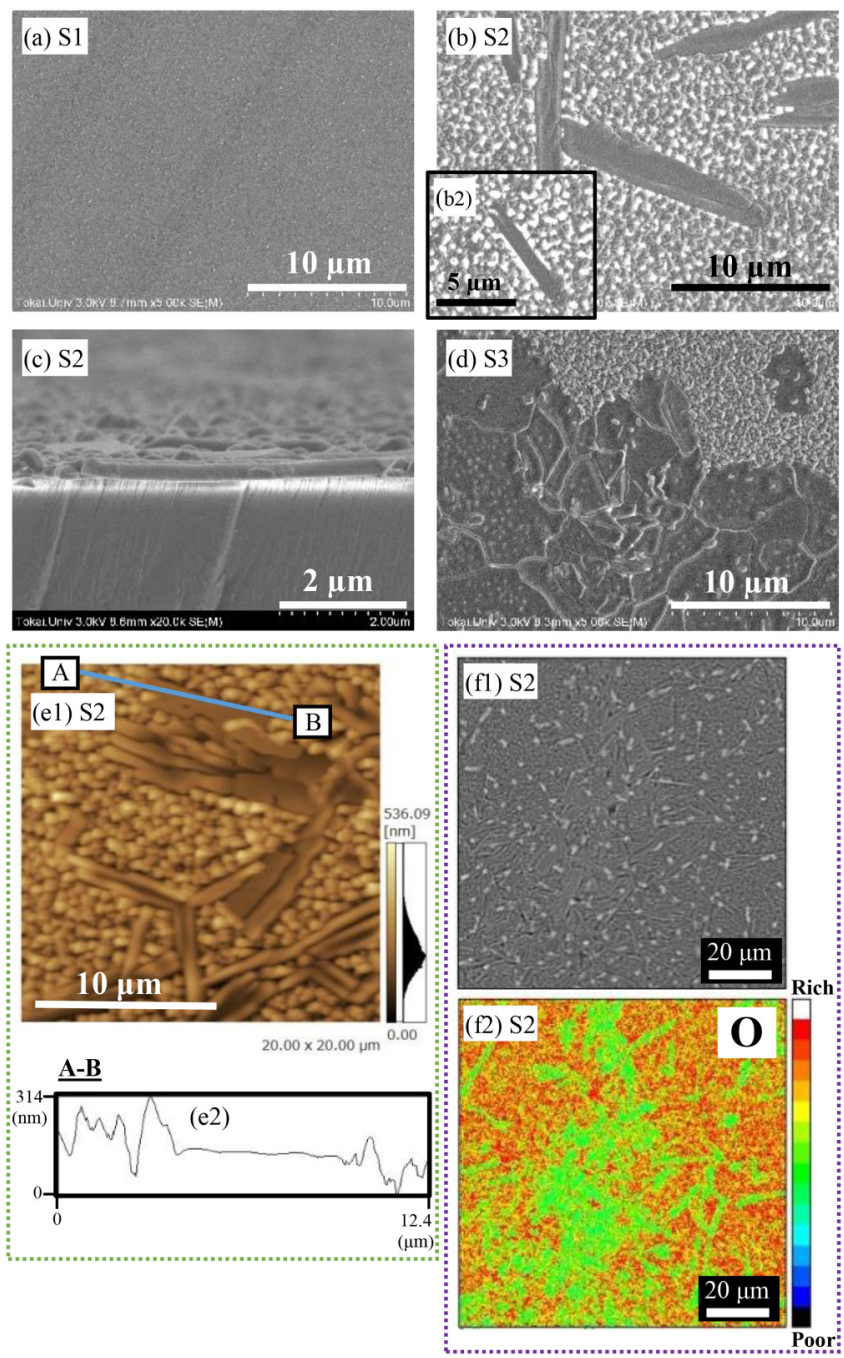

FIG. 2. FE-SEM images for samples S1 (a), S2 (b) and (c), and S3 (d). An AFM image (e1) and the surface profile (e2) for S2. The backscattered electron microscopy (BSE) image (f1) and corresponding EPMA mapping for oxygen concentration (f2) for S2.

suggesting that the thinnest film is composed of (020)-oriented fine crystalline grains. In Fig. 2(b), we found micrometer-sized large crystalline grains in S2 in addition to conventional smaller grains with the (020)-orientation. In the inset of Fig. 2(b), we show another SEM image that clearly shows the platelike crystalline grain with width and length of around $1 \mu \mathrm{m}$ and $6 \mu \mathrm{m}$, respectively. The cross-sectional SEM image for S2 also evidences the presence of a platelike crystallite in Fig. 2(c). When we increased the deposition time to $30 \mathrm{~min}$ in S3, as can be seen in Fig. 2(d), large crystalline grains with a dark contrast were enlarged to more than several tens of micrometer square, although many grain boundaries were present. Such large crystalline grains were confirmed to be 


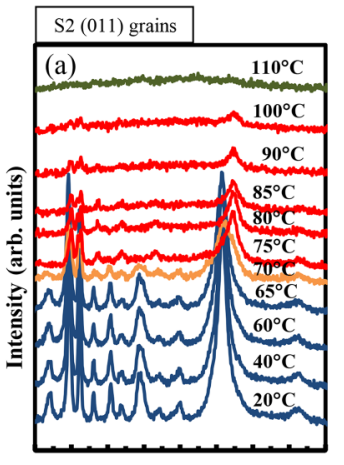

100200300400500600700800900 Wavenumber $\left(\mathrm{cm}^{-1}\right)$

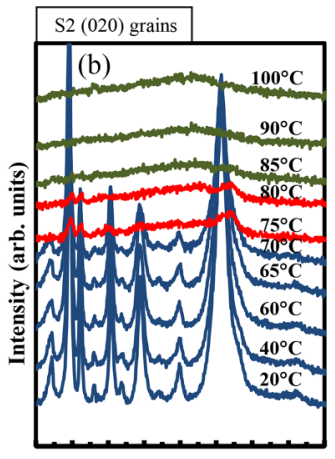

Wavenum
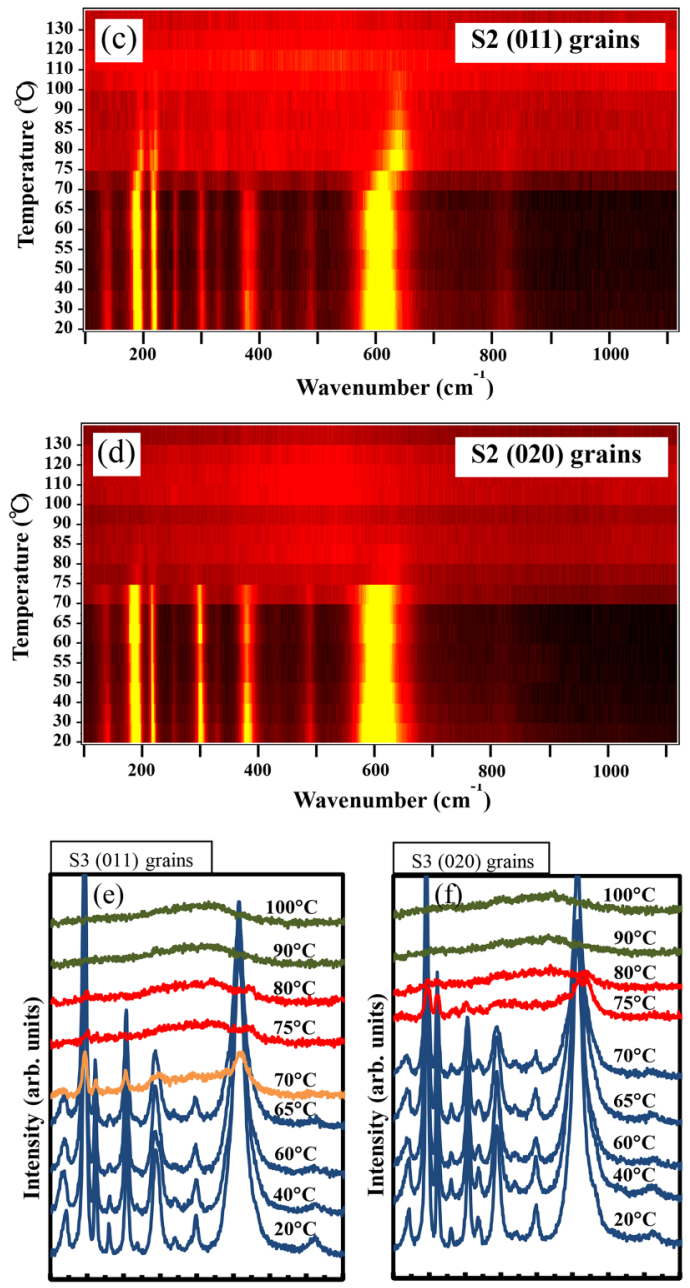

100200300400500600700800900 Wavenumber $\left(\mathrm{cm}^{-1}\right)$

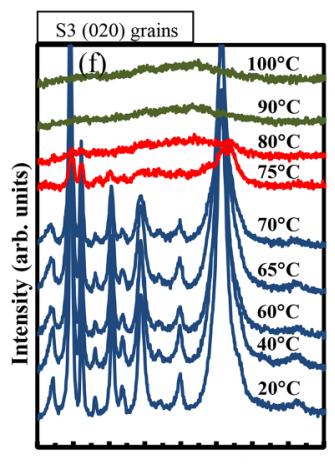

Wavenumber $\left(\mathbf{c m}^{-1}\right)$
FIG. 3. Temperature-dependent micro-Raman spectra for (a) (011)-oriented and (b) (020)-oriented grains in S2. Color plots of Raman spectra for (c) (011)-oriented and (d) (020)-oriented grains in S2. Temperature-dependent micro-Raman spectra for (e) (011)-oriented and (f) (020)-oriented grains in S3. corresponding to the (011)-oriented $\mathrm{VO}_{2}$ by area-restricted XRD measurements, as shown in Fig. A in the supplementary material. Figure 2(e1) shows an AFM image for S2, in which rod-shape crystallites are grown in the fine matrix grains. Height analysis shown in Fig. 2(e2) evidences a flat surface of the crystallite in contrast to matrix grains with rough surfaces and deep grain boundaries. Based on the results of SEM and AFM images, characteristic micrometersized large crystalline grains in S2 were attributed to (011)-oriented crystallites. It can be elucidated that with increasing film thickness, (011)-oriented rod-shape crystallites coalesced and resulted in the formation of large grains. Rod-shape crystallites are no longer observed in S3, suggesting the relaxation of in-plane stress on a particular direction.

Here, it should be noted that glancing incidence XRD (GI-XRD) showed the diffraction from $\mathrm{V}_{6} \mathrm{O}_{13}$ in all samples. $\mathrm{V}_{6} \mathrm{O}_{13}$, which is categorized as one of the Sharley phases with $\mathrm{V}_{\mathrm{n}} \mathrm{O}_{2 n+1}$ like $\mathrm{V}_{2} \mathrm{O}_{5}$, is known to transform to $\mathrm{VO}_{2}$ by annealing because of its quite low melting temperature of $680^{\circ} \mathrm{C} .{ }^{41}$ We elucidate that the (011)-oriented grains were nucleated and grown from the crystalline nuclei of highly oxidized $\mathrm{V}_{6} \mathrm{O}_{13}$ present with (020)-oriented $\mathrm{VO}_{2}$ fine grains. In agreement with this, EPMA mapping images for oxygen $(\mathrm{O})$ concentration in Figs. 2(f1) and 2(f2) show that (011)-oriented large grains contain less $\mathrm{O}$ compared to the surrounding matrix region.

Figure 3(a) shows the results of the temperature-dependent micro-Raman measurement on a particular rod-shape grain in the film S2. The superior crystallinity of the film at room temperature $\left(20^{\circ} \mathrm{C}\right)$ was evidenced by a series of intense peaks corresponding to the $\mathrm{M} 1$ phase $\mathrm{VO}_{2}$. The continuation of the $\mathrm{M} 1$ phase until $65^{\circ} \mathrm{C}$ was clearly recognized. At $70^{\circ} \mathrm{C}$, we recognized the onset of blue shift of the peak at $618 \mathrm{~cm}^{-1}$ (V-O stretching mode in M1). A complete shift of the peak to $648 \mathrm{~cm}^{-1}$ (V-O stretching mode in M2) was clearly observed at $75^{\circ} \mathrm{C}$. Characteristic splitting in the peaks at 220 and $229 \mathrm{~cm}^{-1}$ (the V-V stretching mode in M2) was also recognized, suggesting that a superior crystalline $\mathrm{M} 2$ phase $\mathrm{VO}_{2}$ was formed at this temperature. The M2 phase continued to occur clearly until $100^{\circ} \mathrm{C}$ and then transformed to the R phase completely at $110^{\circ} \mathrm{C}$. Structural phase transition from M1 to M2 with such superior crystallinity and persistent $\mathrm{M} 2$ phase for a range of over $30^{\circ} \mathrm{C}$ is the first observation made in $\mathrm{VO}_{2}$ films grown on $\mathrm{Al}_{2} \mathrm{O}_{3}$ substrates. On the other hand, Fig. 3(b) shows micro-Raman spectra taken for the matrix region, where several tens of namometer grains with (020)-orientation were grown. We also recognize the superior crystallinity of the $\mathrm{M} 1$ phase $\mathrm{VO}_{2}$ at room temperature $\left(20^{\circ} \mathrm{C}\right)$, similar to Fig. 3(a). It can also be seen that the peak at $618 \mathrm{~cm}^{-1}$ showed a blue shift to $648 \mathrm{~cm}^{-1}$ at $75^{\circ} \mathrm{C}$, indicating the appearance of the M2 phase. However, characteristic spectra for M2 phase soon disappeared until $85^{\circ} \mathrm{C}$.

Figures 3(c) and 3(d) show the color plots of temperaturedependence of Raman peak position reproduced from the data shown in Figs. 3(a) and 3(b). An abrupt peak shift from 618 to $648 \mathrm{~cm}^{-1}$ at $75^{\circ} \mathrm{C}$ was clearly demonstrated in Fig. 3(c). On the other hand, the appearance of the M2 phase was hardly recognized for the (020)-oriented area in Fig. 3(d). In order to evaluate the quantitative evolution of the M1, M2, and R phases, we calculated the intensity of Raman peaks by adopting Lorentzian fittings for both (011) and (020)-oriented grains shown in Figs. 3(a) and 3(b). We focused on Raman mode of $619 \mathrm{~cm}^{-1}$ for M1 and $648 \mathrm{~cm}^{-1}$ for M2 phases as 
representatives. To represent the $\mathrm{R}$ phase, which has a strong background for a wide wavenumber range [see Figs. 3(c) and 3(d)], we integrated the intensity for $900-1100 \mathrm{~cm}^{-1}$, where no Raman mode exists in any phase. Through the curve fittings, it was confirmed that the M2 phase appeared simultaneously with the R phase after $65^{\circ} \mathrm{C}$ in both cases. We show the evolution of each phase for both (011) and (020)-grains in Fig. B in the supplementary material.

Furthermore, we performed micro-Raman measurements for the film S3. In Fig. 3(e), we recognize the shifted peak at $648 \mathrm{~cm}^{-1}$ at temperatures from 75 to $80^{\circ} \mathrm{C}$. Also in Fig. 3(f), we recognize the shifted peak from 75 to $80^{\circ} \mathrm{C}$. However, Raman spectra characteristics in the M2 phase were weak compared to those that appeared in the (011)-oriented grain in S2. In our previous paper, we reported the SPT through the $\mathrm{M} 2$ phase in $\mathrm{VO}_{2}$ films deposited on $\mathrm{Al}_{2} \mathrm{O}_{3}(001)$ substrates by using biased reactive sputtering. ${ }^{36,38}$ We elucidated that the formation of (011)-oriented large crystalline grains was driven by a high-energy ion irradiation effect on the excess oxygen phases, which act as nuclei for the growth of (011)-oriented large domains. However, the appearance of the M2 phase was restricted to a narrower temperature range similar to that in Figs. 3(e) and 3(f). Thus, we emphasize that the enhanced crystallinity and persistency of the M2 phase was first demonstrated in this study by taking micro-Raman on the (011)-oriented long grains under high in-plane tensile stress. It is suggested that the appearance of the M2 phase in the course of SPT of $\mathrm{VO}_{2}$ films strongly depends on aspects like crystalline orientation and grain size because they dominate the combined effect of stress on a particular $c_{\mathrm{R}}$-axis direction. ${ }^{42}$ We elucidate that in a highly strained (020)-oriented $\mathrm{VO}_{2}$ film, the appearance of the M2 phase over a wide temperature range is highly unlikely due to the small grain sizes in which the stress effect is relaxed by the grain boundaries. We also show the evolution of the Raman peak intensity of each phase for both (011) and (020)-grains of S3 in Fig. B in the supplementary material.

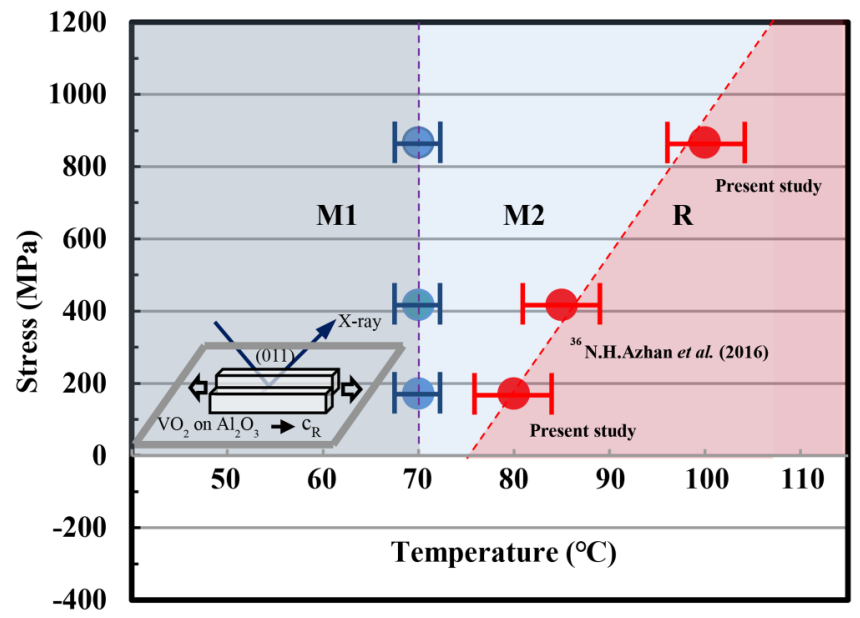

FIG. 4. Stress-temperature phase diagram of structural phase transition (SPT) of M1-M2-R phases for (011)-oriented grains in $\mathrm{VO}_{2}$ films grown on $\mathrm{Al}_{2} \mathrm{O}_{3}(001)$ substrate. Stress values were calculated from the XRD peak position of diffractions from (011)-oriented grains.
Based on the micro-Raman measurements, we drew the phase diagram for M1, M2, and R phases in relation between the stress on (011)-oriented grains and the temperature, as shown in Fig. 4. As mentioned before, we evaluated the in-plane stress values from the out-of-plane strain obtained by the peak position of (011), assuming elastic-body approximation with Young's modulus and Poisson's ratio of $140 \mathrm{GPa}$ and 0.30 , respectively. The stress values for (011)-oriented grains for samples S2 and S3 are 860 and $165 \mathrm{MPa}$, respectively. From the results, it can be seen that increasing tensile stress induces a wider temperature window for the M2 phase. The high-temperature side was extended by the increasing stress, while the lowest temperature side for the M2 phase was rather constant at around $70^{\circ} \mathrm{C}$. The added data for the $\mathrm{VO}_{2}$ film with (011)-oriented large domains were based on the peak position of XRD presented in our previous paper, ${ }^{36}$ supporting the validity of the proposed phase space regardless of the difference in the deposition method. The boundary between M2 and R phases obtained by the present study for sample S2 almost corresponds to the extrapolated line based on the result of Park et al. ${ }^{43}$ The present result, in which the crystalline grain under a strong tensile stress of $0.86 \mathrm{GPa}$ shows a persistent $\mathrm{M} 2$ phase until $100^{\circ} \mathrm{C}$, suggested an invariant nature of SPT in $\mathrm{VO}_{2}$. On the other hand, it can be seen that the boundary from the M1 to M2 phases obtained by the present study was different from that using $\mathrm{VO}_{2}$ nanobeams. ${ }^{28,30,43}$ SPT from M1 to M2 was observed at an almost constant temperature of around $70^{\circ} \mathrm{C}$ in our study. As shown in Fig. 3(b), (020)-oriented grains showed the onset of SPT at $70^{\circ} \mathrm{C}$, the same as the onset of (011)-oriented grains.

Here, we consider the cause for a simultaneous onset for the appearance of the M2 phase for both (011) and (020)-oriented grains. When discussing the SPT of $\mathrm{VO}_{2}$, it is necessary to compare the lattice length toward the $c_{\mathrm{R}}$ direction. The monoclinic M2 phase has been reported to have a lattice length of $a_{\mathrm{M} 2}=9.0664 \AA$, $b_{\mathrm{M} 2}=5.797 \AA, c_{\mathrm{M} 2}=4.5255 \AA$, and $\beta_{\mathrm{M} 2}=91.88^{\circ}$. ${ }^{20}$ Meanwhile, as is well known, the M1 phase has $a_{\mathrm{M} 1}=5.753 \AA, b_{\mathrm{M} 1}=4.526 \AA$, $c_{\mathrm{M} 1}=5.383 \AA$, and $\beta_{\mathrm{M} 1}=122.6^{\circ}$ and the tetragonal rutile phase has $a_{\mathrm{R}}=4.555 \AA$ and $c_{\mathrm{R}}=2.853 \AA{ }^{20}$ Thus, the corresponding lattice length of $a_{\mathrm{M} 1}, 2 c_{\mathrm{R}}$, and $b_{\mathrm{M} 2}$ are 5.753, 5.706, and $5.797 \AA$, respectively. The length would then be compressed by $-0.8 \%$ upon M1 to $\mathrm{R}$ transition, while it would be tensiled by $0.76 \%$ upon M1 to M2 transition. As Zhang et al. suggested, the compression upon M1 to $\mathrm{R}$ phase transition induces tensile stress, which can locally stabilize the formation of the M2 phase with a large cell length of $b_{\mathrm{M} 2}{ }^{27}$ Thus, the formation of the M2 phase follows nucleation of the $\mathrm{R}$ phase. In addition, the onset of SPT of (011)-oriented grains will be strongly restricted by the surrounding (020)-oriented matrix grains. When $\mathrm{VO}_{2}$ transforms from the $\mathrm{M} 1$ to the $\mathrm{M} 2$ phase, the unit cell volume increases by about $0.66 \%$ with in-plane enlargement for $2 V_{\mathrm{M} 1} \rightarrow V_{\mathrm{M} 2}$. Then, the SPT of M1 to M2 would be severely restricted by the unchanged surrounding matrix. Therefore, we interpret that the (011)-oriented grains revealed the SPT from M1 to M2 at temperatures corresponding to that from M1 to R of (020) grains. Naturally, the SPT of (020) grains from M1 to M2 occurs simultaneously. As shown in Fig. 3, the peak intensity of the M2 phase in the (020) grains was smaller than that of the (011) grains in S2. Therefore, we interpret that a simultaneous onset of the appearance of the M2 phase for both (011) and (020)-oriented grains occurred at a temperature at which SPT from 
the M1 to the R phase was initiated. On the other hand, the SPT from $\mathrm{M} 2$ to $\mathrm{R}$ is accompanied by a slight volume decrease of $0.40 \%$, which enables (011)-oriented grains' transformation according to the stress-temperature phase diagram.

Kim et al. reported that single-crystal $\mathrm{VO}_{2}$ wires with a length over $10 \mu \mathrm{m}$ grown on an $\mathrm{r}$-cut sapphire substrate possess M2 phase, which are stable from 19 to $100^{\circ} \mathrm{C}$. ${ }^{44}$ They expected that thicker wires with greater stress supplied sufficient driving force to nucleate the M2 phase in addition to the effect of substrate-mediated interaction. Thus, we interpret that the growth of large grains with superior crystallinity is a key issue to emerge persistent M2 phase. Furthermore, the occurrence of the $\mathrm{M} 2$ phase in $\mathrm{VO}_{2}$ films on $\mathrm{Al}_{2} \mathrm{O}_{3}$ (001) substrates was reported by Ji et al. ${ }^{22}$ They mentioned that the temperature window for the M2 phase depends on the
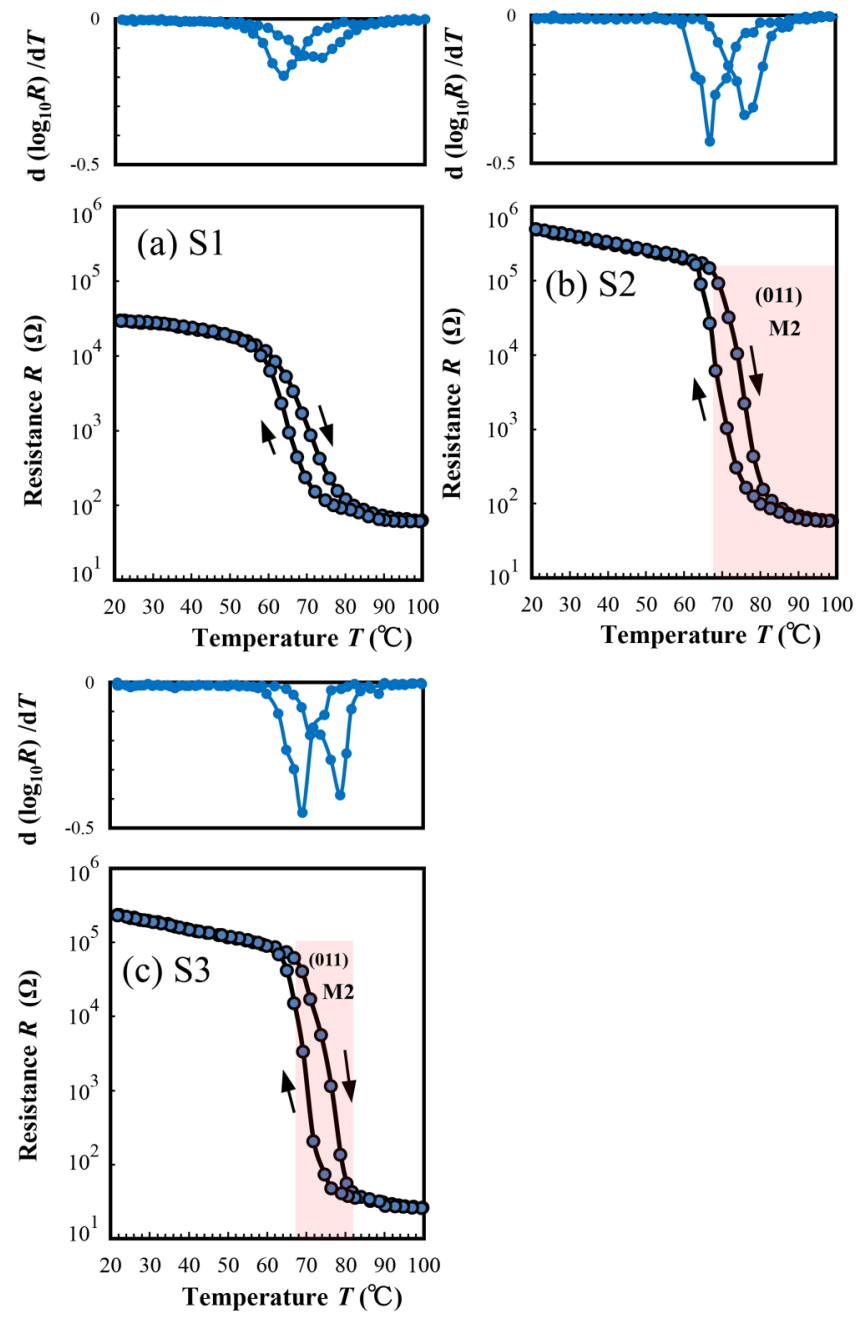

FIG. 5. Resistance (R)-temperature $(T)$ characteristics for $S 1, \mathrm{~S} 2$, and $\mathrm{S} 3$ films. Numerical values of derivative of resistance against temperature $\left[\mathrm{d}\left(\log _{10} R\right) / \mathrm{d} T\right]$ were also plotted in the top part of the figure in which temperature axes are common with $R$ - $T$ panels. tensile strain that is relevant to the film thickness. Thus, in the present study, the large in-plane tensile stress in (011)-oriented grains in S2 contributes to an enlargement of the window for the M2 phase, as shown in Fig. 4.

Finally, we show resistance $(R)$-temperature $(T)$ characteristics for S1, S2, and S3 films in Fig. 5. Resistance was measured by two probe tips separated by $1 \mathrm{~mm}$. As can be seen, change in resistance above three orders of magnitude was observed after the onset of the IMT in both S2 and S3. Values of the transition temperature defined by the peak of $-\mathrm{d}\left(\log _{10} R\right) / \mathrm{d} T$ against the rising temperature were 77 and $79^{\circ} \mathrm{C}$ for S2 and S3, which were higher than those of $\mathrm{S} 1\left(75^{\circ} \mathrm{C}\right)$. Resistance started to decrease with the onset of SPT at around $70^{\circ} \mathrm{C}$ in both S2 and S3. As shown in temperature-dependent Raman measurements, the $\mathrm{R}$ phase increases its domination in accordance with the decrease in the M1 phase at a temperature of $70^{\circ} \mathrm{C}$. Although the $\mathrm{M} 2$ phase appeared at this temperature in both (011) and (020) grains, resistance continued to decrease due to the current flow through the $\mathrm{R}$ phase. It can be observed in both S2 and S3 that the resistance almost reached its lowest values soon after the M2 phase for the (020) grains disappeared. We marked the temperature ranges of the M2 phase for (011) grains based on the results of Fig. 3. Even in sample S2, the apparent influence of the M2 phase on resistance was not recognized because the current path between the two probe tips could be formed through the $\mathrm{R}$ phase area with a low resistivity. It is required to evaluate other physical properties such as optical reflectance and transmittance of infrared light with high spatial resolution in order to evaluate the effect of the persistent M2 phase in (011)-oriented grains. A combination of far-field infrared spectroscopy and near-field infrared microscopy will be effective for monitoring the coexisting insulating M2 and metallic R phases through the difference in optical characteristics including optical conductivity. ${ }^{45}$

\section{CONCLUSIONS}

The persistent M2 phase in strongly strained (011)-oriented grains in $\mathrm{VO}_{2}$ films grown on $\mathrm{Al}_{2} \mathrm{O}_{3}$ (001) substrates by means of conventional rf magnetron sputtering was first demonstrated. Temperature-dependent micro-Raman measurements showed the appearance of an M2 phase from 70 to $100^{\circ} \mathrm{C}$ in (011)-oriented grains, in contrast to a narrower range of $10^{\circ} \mathrm{C}$ in (020)-oriented matrix grains. It is suggested that the appearance of the $\mathrm{M} 2$ phase in the course of the SPT of $\mathrm{VO}_{2}$ films strongly depends on factors like crystalline orientation and grain sizes because they dominate the combined effect of stress on a particular $c_{\mathrm{R}}$-axis direction.

\section{SUPPLEMENTARY MATERIAL}

See the supplementary material for the (Fig. A) area-restricted XRD and SEM images for S3 and (Fig. B) integrated signal intensity of M1, M2, and R phases estimated by adopting Lorentzian fittings for Raman spectra of S2 and S3.

\section{ACKNOWLEDGMENTS}

This work was supported by a Grant-in-Aid for Scientific Research (Grant No. 15K04652) from the Japan Society for the Promotion of Science. 


\section{REFERENCES}

${ }^{1}$ T. C. Chang, X. Cao, S.-H. Bao, S.-D. Ji, H.-J. Luo, and P. Jin, Adv. Manuf. 6, 1 (2018).

${ }^{2}$ S. Wang, L. Kang, and D. H. Werner, Sci. Rep. 8, 189 (2018).

${ }^{3}$ Y. Zou and S. Ramanathan, Proc. IEEE 103, 1289 (2015).

${ }^{4}$ Z. Yang, C. Ko, and S. Ramanathan, Annu. Rev. Mater. Res. 41, 337 (2011).

${ }^{5}$ M. M. Qazilbash, M. Brehm, B.-G. Chae, P.-C. Ho, G. O. Andeev, B.-J. Kim, S. J. Yun, A. V. Balatsky, M. B. Maple, F. Keilmann, H.-T. Kim, and D. N. Basov, Science 318, 1750 (2007).

${ }^{6}$ J. Sakai, J. Appl. Phys. 103, 103708 (2008).

${ }^{7}$ H.-T. Kim, B.-J. Kim, S. Choi, B.-G. Chae, Y. W. Lee, T. Driscoll, M. M. Qazilbash, and D. N. Basov, J. Appl. Phys. 107, 023702 (2010).

${ }^{8}$ J. Leroy, A. Crunteanu, J. Givernaud, J. C. Orlianges, C. Champeaux, and P. Blondy, Int. J. Microw. Wirel. Technol. 4, 101 (2012).

${ }^{9}$ G. Sun, X. Cao, X. Li, S. Bao, N. Li, M. Liang, A. Gloter, H. Gu, and P. Jin, Sol. Energy Mater. Sol. Cells 161, 70 (2017).

${ }^{10}$ M. A. Kats, R. Blanchard, S. Zhang, P. Genevet, C. Ko, S. Ramanathan, and F. Capasso, Phys. Rev. X 3, 041004 (2013).

${ }^{11}$ K. Ito, K. Nishikawa, and H. Iizuka, Appl. Phys. Lett. 108, 053507 (2016).

${ }^{12}$ N. Shukla, A. Parihar, E. Freeman, H. Paik, G. Stone, V. Narayan, H. Wen, Z. Cai, V. Gopalan, R. Engel-Herbert, D. G. Schlom, A. Raychowdhury, and S. Dutta, Sci. Rep. 4, 4964 (2014).

${ }^{13}$ L. Gao, P.-Y. Chen, and S. Yu, Appl. Phys. Lett. 111, 103503 (2017).

${ }^{14}$ M. Liu, H. Y. Hwang, H. Tao, A. C. Strikwerda, K. Fan, G. R. Keiser, A. J. Sternbach, K. G. West, S. Kittiwatanakul, J. Lu, S. A. Wolf, F. G. Omenetto, X. Zhang, K. A. Nelson, and R. D. Averitt, Nature 487, 345 (2012).

${ }^{15}$ Y. Nakata, Y. Urade, K. Okimura, T. Nakanishi, F. Miyamaru, M. W. Takeda, and M. Kitano, Phys. Rev. Appl. 6, 044022 (2016).

${ }^{16}$ Y. Muraoka and Z. Hiroi, Appl. Phys. Lett. 80, 583 (2002).

${ }^{17}$ K. Nagashima, T. Yanagida, H. Tanaka, and T. Kawai, Phys. Rev. B 74, 172106 (2006).

${ }^{18} \mathrm{~K}$. Shibuya, J. Tatsumi, T. Hasegawa, and A. Sawa, Appl. Phys. Lett. 103, 021604 (2013).

${ }^{19}$ M. Nakano, K. Shibuya, D. Okuyama, H. Hatano, S. Ono, M. Kawasaki, Y. Iwasa, and Y. Tokura, Nature 487, 459 (2012).

${ }^{20}$ M. Marezio, D. B. McWhan, J. P. Remeika, and P. D. Dernier, Phys. Rev. B 5, 2541 (1972).

${ }^{21}$ J. P. Pouget, H. Launois, T. M. Rice, P. Dernier, A. Gossard, G. Villeneuve, and P. Hagenmuller, Phys. Rev. B 10, 1801 (1974).

${ }^{22}$ Y. Ji, Y. Zhang, M. Gao, Z. Yuan, Y. Xia, C. Jin, B. Tao, C. Chen, Q. Jia, and Y. Lin, Sci. Rep. 4, 4854 (2014).
${ }^{23}$ S.-H. Kim, B.-J. Kim, T.-Y. Jeong, Y.-S. Lee, and K.-J. Yee, J. Appl. Phys. 117, 163107 (2015).

${ }^{24}$ H. Kim, T. V. Slusar, D. Wulferding, L. Yang, J.-C. Cho, M. Lee, H. C. Choi, Y. H. Jeong, H.-T. Kim, and J. Kim, Appl. Phys. Lett. 109, 233104 (2016).

${ }^{25}$ M. Nazari, Y. Zhao, Z. Y. Fan, K. Ziemer, A. A. Bernussi, and M. Holtz, J. Phys. D Appl. Phys. 48, 135101 (2015).

${ }^{26}$ J. I. Sohn, H. J. Joo, D. Ahn, H. H. Lee, A. E. Porter, K. Kim, D. J. Kang, and M. E. Welland, Nano Lett. 9, 3392 (2009).

27. Zhang, J. Y. Chou, and L. J. Lauhon, Nano Lett. 9, 4527 (2009).

${ }^{28}$ J. Cao, Y. Gu, W. Fan, L. Q. Chen, D. F. Ogletree, K. Chen, N. Tamura, M. Kunz, C. Barrett, J. Seidel, and J. Wu, Nano Lett. 10, 2667 (2010).

${ }^{29}$ W. Fan, J. Cao, J. Seidel, Y. Gu, J. W. Yim, C. Barrett, K. M. Yu, J. Ji, R. Ramesh, L. Q. Chen, and J. Wu, Phys. Rev. B 83, 235102 (2011).

${ }^{30}$ J. A. Atkin, S. Berweger, E. K. Chavez, M. B. Raschke, J. Cao, W. Fan, and J. Wu, Phys. Rev. B 85, 020101(R) (2012).

${ }^{31}$ J. I. Sohn, H. J. Joo, K. S. Kim, H. W. Yang, A. -Rang Jang, D. Ahn, H. H. Lee, S. Cha, D. J. Kang, J. M. Kim, and M. E. Welland, Nanotechnology 23, 205707 (2012).

${ }^{32}$ V. Thery, A. Boulle, A. Crunteanu, J. C. Orlianges, A. Beaumont, R. Mayer, A. mennai, F. Cosset, A. Bessaudou, and M. Fabert, Phys. Rev. B 93, 184106 (2016).

${ }^{33}$ J. Jian, A. Chen, Y. Chen, X. Zhang, and H. Wang, Appl. Phys. Lett. 111, 153102 (2017).

${ }^{34}$ K. Okimura and J. Sakai, Jpn. J. Appl. Phys. 48, 045504 (2009).

${ }^{35}$ H. Katzke, P. Toledano, and W. Depmeier, Phys. Rev. B 68, 024109 (2003).

${ }^{36} \mathrm{~N}$. H. Azhan, K. Su, K. Okimura, M. Zaghrioui, and J. Sakai, J. Appl. Phys. 117, 245314 (2015).

${ }^{37}$ K. Okimura, J. Sakai, and S. Ramanathan, J. Appl. Phys. 107, 063503 (2010).

${ }^{38} \mathrm{~N}$. H. Azhan, K. Okimura, K. Matsuoka, M. Zaghrioui, and J. Sakai, J. Vac. Sci. Technol. A 35, 061508 (2017).

${ }^{39}$ M. Zaghrioui, J. Sakai, N. H. Azhan, K. Su, and K. Okimura, Vib. Spectrosc. 80, 79 (2015)

${ }^{40} \mathrm{Q}$. Luo and A. H. Jones, Surf. Coat. Technol. 205, 1403 (2010).

${ }^{41}$ C. Cheng, K. Liu, B. Xiang, J. Suh, and J. Wu, Appl. Phys. Lett. 100, 103111 (2012)

${ }^{42}$ M.-W. Kim, W.-G. Jung, H. Cho, T.-S. Bae, S.-J. Chang, J.-S. Jang, W.-K. Hong, and B.-J. Kim, Sci. Rep. 5, 10861 (2015).

${ }^{43}$ J. H. Park, J. M. Coy, T. S. Kasirga, C. Huang, Z. Fei, S. Hunter, and D. H. Cobden, Nature 500, 431 (2013).

${ }^{44}$ M.-W. Kim, S.-S. Ha, O. Seo, D. Y. Noh, and B.-J. kim, Nano Lett. 16, 4074 (2016).

${ }^{45}$ M. M. Qazilbash, M. Brehm, G. O. Andreev, A. Frenzel, P.-C. Ho, B.-G. Chae, B.-J. Kim, S. J. Yun, H.-T. Kim, A. V. Balatsky, O. G. Shpyrko, M. B. Maple, F. Keilmann, and D. N. Basov, Phys. Rev. B 79, 075107 (2009). 